\title{
La cerámica aplicada en arquitectura: hacia una normalización de los criterios de intervención
}

\author{
Juan José Lupión Álvarez y María Arjonilla Álvarez
}

Resumen: Como fiel reflejo del progresivo aumento de sensibilización de nuestra cultura, se fomentan las continuas revisiones de los acuerdos internacionales en materia de conservación y restauración, en pro de la normalización de las actuaciones sobre las distintas manifestaciones del patrimonio tangible. En esta línea, se propone la reflexión crítica en torno a una tipología de bienes clasificados entre los inmuebles, por su relación directa con los revestimientos arquitectónicos: la cerámica.

Los criterios de intervención que se aplican en la actualidad están fuertemente condicionados por su entorno y función. Para una necesaria propuesta de normalización en las actuaciones, debemos comenzar por revisar el estado de la cuestión.

Palabras clave: Cerámica, intervención, normalización, criterio.

Resumo: Reflectindo fielmente o progressivo aumento da consciência da nossa cultura, fomentam-se contínuas revisões dos acordos internacionais em matéria de conservação e restauro, em prol da normalização das actuações sobre as distintas manifestações do património tangível. Nesta linha, propõe-se a reflexão crítica em torno de uma tipologia de bens classificados entre os imóveis, pela sua relação directa com os revestimentos arquitectónicos: a cerâmica.

Os critérios de intervenção que se aplicam na actualidade estão fortemente condicionados pelo seu contexto e função. Para uma necessária proposta de normalização das acções, devemos começar por rever o estado da questão.

Palavras-chave: Cerâmica, intervenção, normalização, critério.

Abstract: To reflect faithfully the gradually increasing awareness of our culture, continual revision of international agreements in preservation and restoration is encouraged in favour of standard proceedings for the different expressions of our tangible heritage. Along these lines, critical thought is proposed for a typology of assets classified as real estate because of their intrinsic relationship with architectural facings such as ceramic tiling. The criteria of intervention that are currently applied are strongly determined by his environment and function. For a necessary offer of normalization in the actions, we must begin inspecting the state of affairs.

Keywords: Tiled surfaces, intervention, standardization, criteria.

\section{Antecedentes}

El concepto de Bien Cultural otorgó una nueva valoración a los objetos artísticos, y amplió el espectro de protección a la diversidad de manifestaciones del patrimonio material e inmaterial de cada pueblo. Como quedó definido por la UNESCO, los bienes dotados de valor de civilización son considerados como testimonios del pasado y del presente. A los valores históricos o artísticos, ahora sumamos los referidos a la identidad del Bien dentro de la comunidad que lo ha realizado o mantenido en el tiempo. No es solo su cualidad estética, o su singularidad; la valoración vigente se 
basa en la representatividad de ese Bien, en las señas de identidad, lo que su esencia significa para una comunidad. Este nuevo concepto ha propiciado la revalorización de ciertas actividades y obras, en razón a sus aspectos paleontológicos, arqueológicos, etnográficos, científicos o técnicos. Entre las tipologías artísticas ha significado también la necesaria puesta en valor de las producciones y artefactos, que hasta hace poco tiempo venían encuadrados bajo la consideración de Artes Menores. En este grupo se englobaba la cerámica, objeto de nuestro estudio, concretamente la cerámica aplicada a la arquitectura.

En el caso de Andalucía, el patrimonio cerámico es especialmente importante, por la fuerte tradición cultural aún hoy vigente. En Sevilla, la práctica árabe de los zócalos de alicatado (con pequeñas piezas independientes que forman combinaciones geométricas), y de cuerda seca (piezas de forma regular donde los esmaltes polícromos se separan con una línea de grasa) derivó en un método más productivo conocido como azulejería de cuenca ${ }^{1}$. A finales del siglo XV, la llegada a la ciudad del ceramista italiano Niculoso Francisco ${ }^{2}$, incorpora la innovadora técnica del azulejo plano. Una técnica que ganaría rápidamente seguidores y cuya producción resurge con gran vigor en el siglo XVI, para adornar palacios, edificios notables, templos, conventos, utilizándose en zócalos, cuadros devocionales y frontales para mesas de altar (Lupión 2006).

Un rico patrimonio que se ha mantenido vivo a través de la historia, y que sin embargo, sigue sufriendo en la mayoría de las culturas la debida valoración. Podríamos afirmar que esto ha sido y sigue siendo la principal causa de degradación de la cerámica aplicada a la arquitectura.

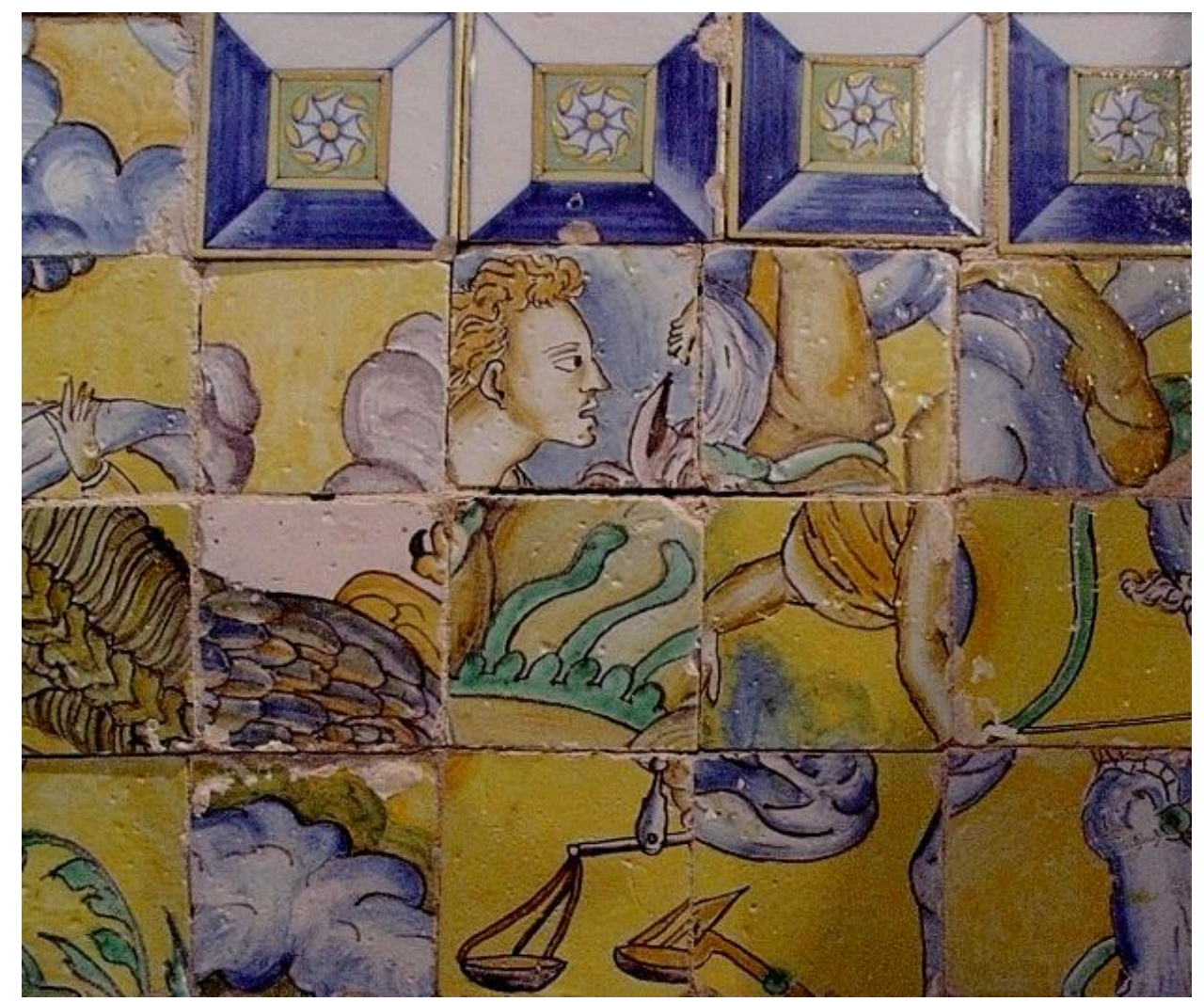

Figura 1. Panel cerámico desordenado en un frontal de altar. Iglesia del Convento de Madre de Dios, Sevilla (J.J. Lupión) 
Las rehabilitaciones, reconversiones, remodelaciones, transformaciones, "puestas en valor" y rentabilización del patrimonio arquitectónico han traído, como consecuencia, la subordinación y el detrimento de la atención que se presta a estos elementos considerados secundarios, en beneficio de la función, nueva o no, del Bien Inmueble. Pero la falta de reconocimiento y valoración de los aspectos culturales de la cerámica aplicada a la arquitectura, se está corrigiendo. Y prueba de ello es la adopción de una nueva categoría de materiales: de la expresión "revestimientos arquitectónicos cerámicos", vemos la tendencia a englobar esta tipología bajo un nuevo epígrafe "cerámica aplicada en Arquitectura".

Conceptualmente, la cerámica se ha puesto en valor por sí misma, más allá de su utilidad funcional o decorativa, en relación con la arquitectura en que se adosa y en el contexto cultural en que se creó. Es el primer paso para su mejor conservación.

Pero no podemos olvidar que la cerámica aplicada en arquitectura encierra una especial problemática a la hora de abordar una intervención de conservación-restauración. Su patología es directamente dependiente de la patología del inmueble. Por tanto, la conservación preventiva de la cerámica incluye y necesita en la mayoría de los casos de una intervención arquitectónica restauradora. Sin embargo, no se trata de actuar en un simple material de revestimiento, interviniendo o reparando con intención estética. Se trata de actuar en las causas que originan la degradación y de mantener dignamente el original. Es un cambio de planteamiento, o simplemente la puesta en valor de la cerámica.

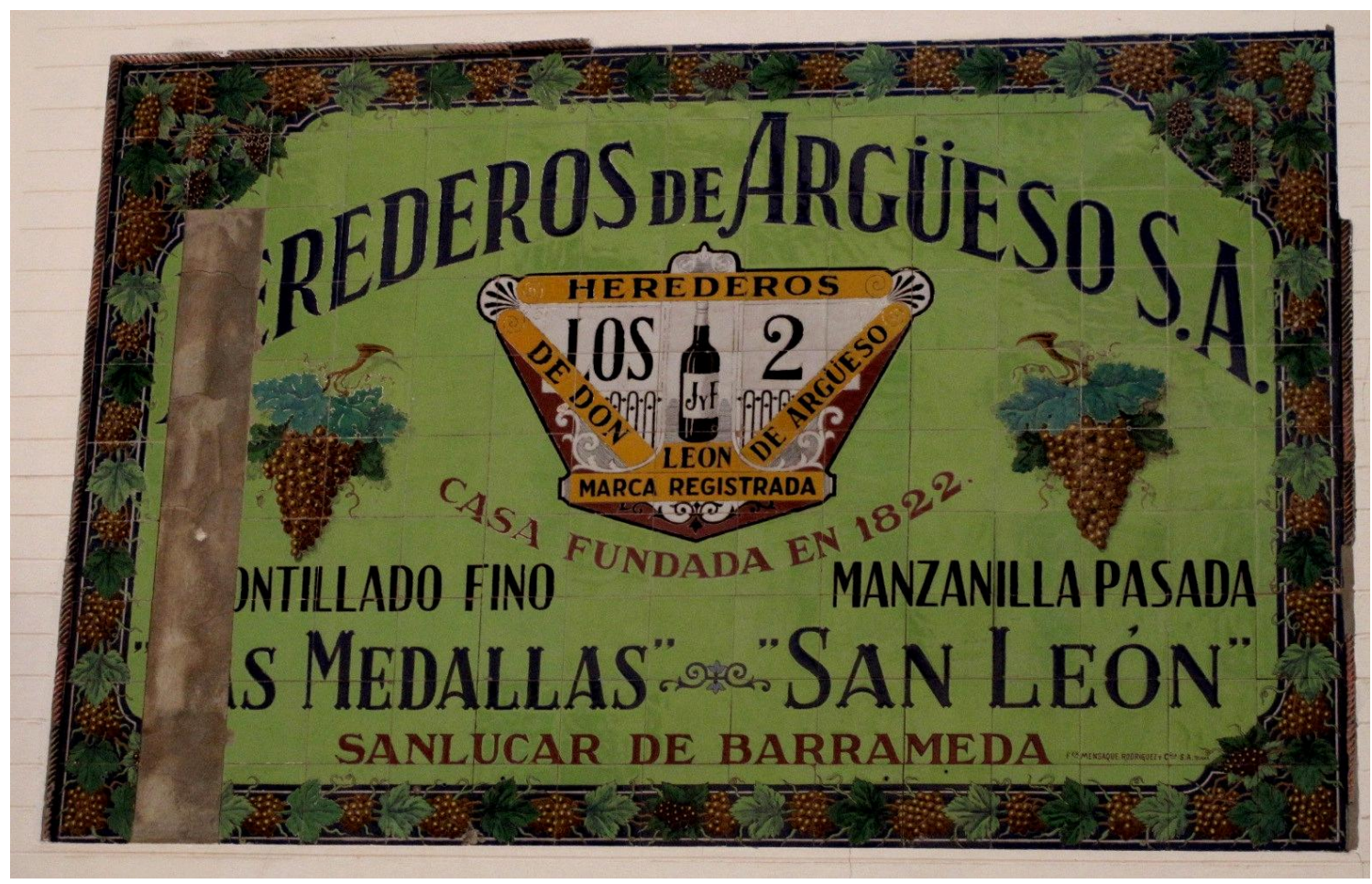

Figura 2. Destrucción intencionada de piezas en un zócalo publicitario, para acceder a la reparación de canaleta interna. Plaza de Europa, Sevilla (M. Arjonilla). 
Estos bienes suelen contar además con una dificultad añadida cuando su emplazamiento está en el exterior del edificio, ya que esto condiciona y complica los métodos de intervención, en cuanto a la durabilidad de los materiales expuestos a la intemperie. Este hecho puede afectar a la conservación de la cerámica desde el punto de vista preventivo, y además, derivan en una problemática particular cuando se trata de actuar desde la conservación directa y la restauración.
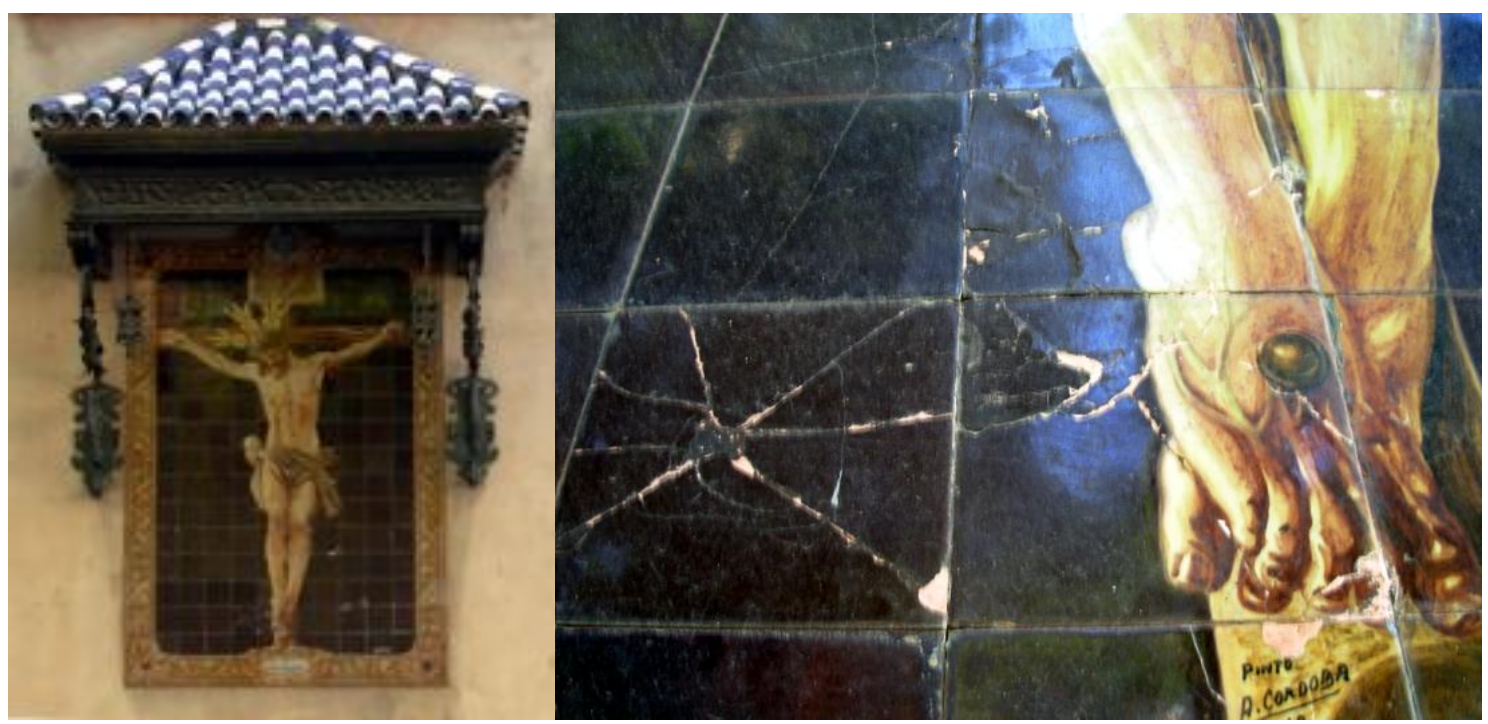

Figura 3. Actos de vandalismo, en un panel religioso. Iglesia de la Magdalena, Sevilla (J.J. Lupión).

Hemos de señalar también como grave agente de deterioro el vandalismo: la pérdida o sustracción de elementos es frecuente, debido a la facilidad con la que pueden extraerse las piezas cuando la degradación se produce en los morteros de sujeción. El expolio de la azulejería antigua en las reformas de inmuebles ha hecho que exista un mercado especializado en estos bienes.

Si nos metemos de lleno en los criterios de actuación más usuales, nos encontramos con una problemática general derivada de la función del material cerámico: las nuevas piezas incluidas en los procesos de restauración para la reintegración de lagunas y faltantes. No existe material más perdurable al exterior o bajo condiciones climáticas extremas tan duradero como el cerámico. Lo cual ha incidido en el usual criterio de sustitución. Sus características intrínsecas hacen que la cerámica se exponga a las más duras condiciones ambientales: la humedad por capilaridad, la exposición directa a las inclemencias meteorológicas, la dureza de agua, la invasión de sales solubles e insolubles... Su uso como pieles de sacrificio o de protección de estructuras, la falta de control en la puesta en obra, etc. hacen necesario establecer una praxis de cara a la normalización en las actuaciones.

\section{Concepto de criterio y notas históricas}

Los criterios3, en el ámbito de la conservación y restauración, son los principios teóricos o normas generales que sirven de guía en la toma de decisiones, a la hora de intervenir sobre el patrimonio. No existe un único criterio, y en la práctica, cuando se realiza de forma responsable, la diversidad de las propuestas busca la armonización, para conseguir una correcta conservación del Bien Cultural. Sin embargo, a lo largo de la historia, las diferentes teorías de la restauración han propugnado postulados enfrentados: los criterios han venido siempre supeditados a la forma en la 
que se aprecia el bien. En nuestra sociedad actual, el patrimonio se valora por su interés colectivo y universal, desde la civilización que lo genera.

Una de las primeras referencias de importancia que debemos destacar son los principios teóricos enunciados por Cesare Brandi4. Basados en la necesidad de protección del patrimonio, y en la búsqueda de normas unificadas en favor del mayor respeto a la autenticidad. Su principal objetivo era poner fin a la errónea praxis de restauración mediante restituciones integrales.

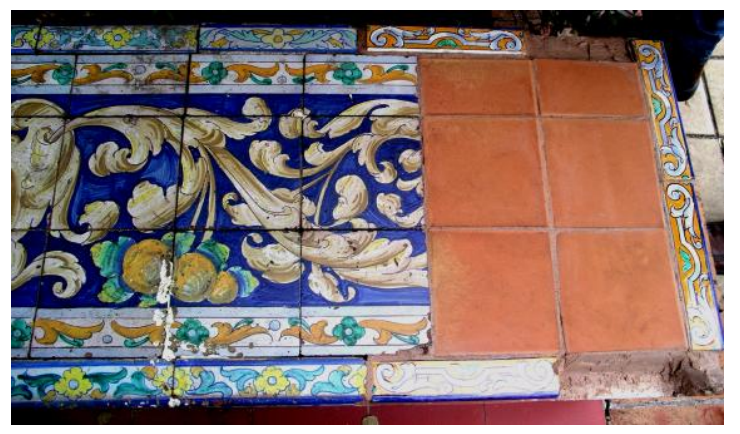

Figuras 4 y 5. Una misma forma de entender la reparación con piezas cerámicas sobre dos paños con distinta función: asiento de banco (Pza. de España, Sevilla) y zócalo publicitario (Pza. de Europa, Sevilla). (M. Arjonilla y J.J. Lupión).

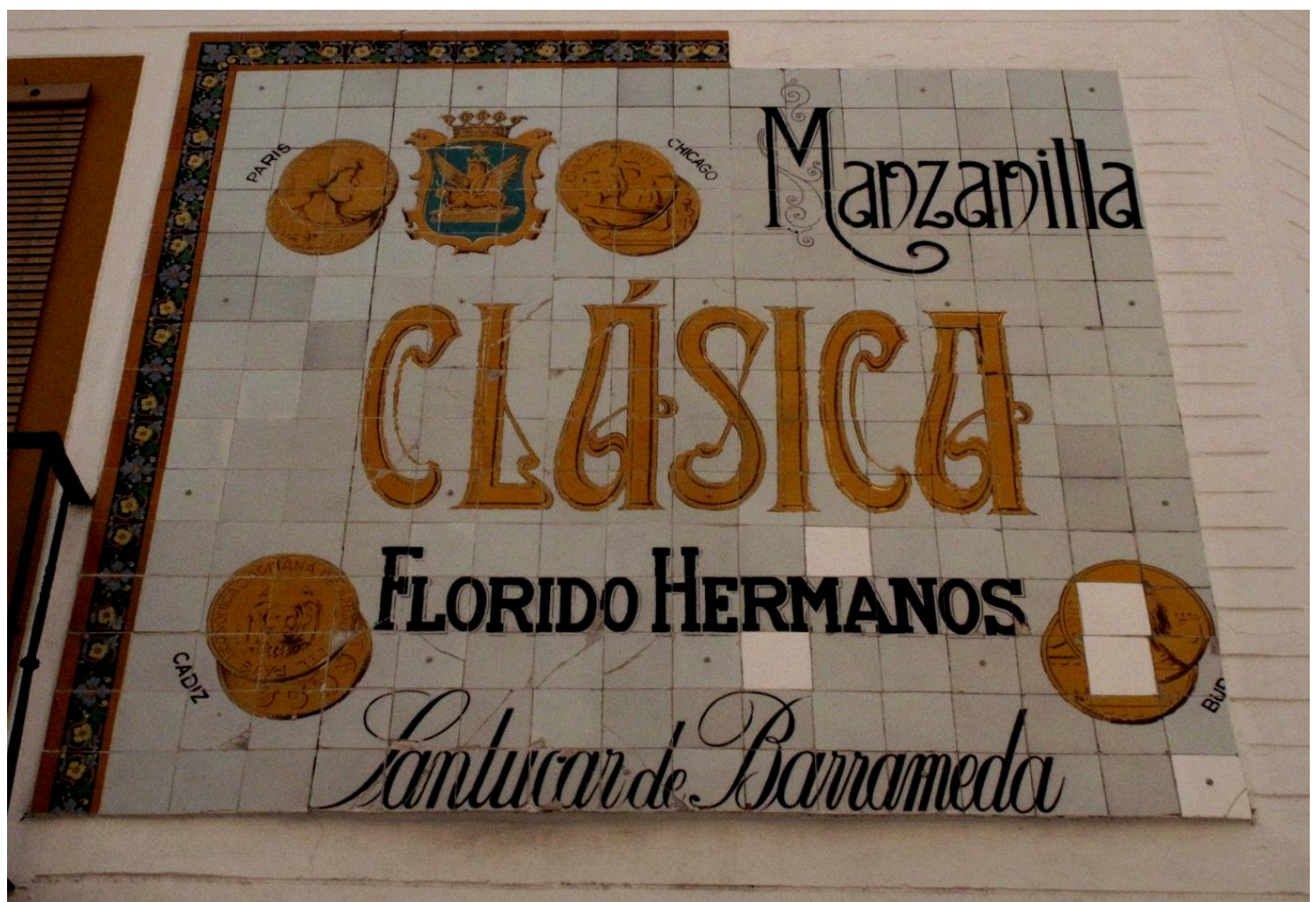

Se han redactado distintas normativas, recomendaciones y cartas. Uno de los primeros documentos aceptados internacionalmente fue concebido en Italia, la Carta del Restauro de 1932. Aunque se limitaba a los monumentos arquitectónicos, las normas propuestas constituyeron un referente para todas las intervenciones sobre patrimonio. La creación del Istituto Centrale del Restauro en 1938, fue fruto del incremento de concienciación sobre los peligros a los que una restauración realizada sin los oportunos criterios técnicos, exponía a las obras de arte.

Los sucesivos acuerdos y legislaciones nacionales e internacionales, suponen un logro para la normalización de las distintas cuestiones relativas a la conservación y restauración. Actualmente 
organismos, como la UNESCO ${ }^{5}$ y el Consejo de Europa $^{6}$, promueven la cooperación internacional en materia de Patrimonio Cultural, favoreciendo acuerdos a nivel mundial en relación a los principios éticos elementales, mediante el intercambio del conocimiento y la elaboración de instrumentos normativos y jurídicos.

En nuestro país, la normativa vigente define al Instituto del Patrimonio Cultural de España (IPCE), cuyo precedente es el Instituto de Conservación y Restauración de Bienes Culturales (ICRBC) ${ }^{7}$, como organismo responsable de establecer las líneas prioritarias de investigación en criterios, métodos y técnicas de conservación y restauración de dicho Patrimonio.

Y en el caso de la Comunidad Andaluza, y desde su creación en 1989, le corresponde al Instituto Andaluz del Patrimonio Histórico (IAPH), de la Consejería de Cultura de la Junta de Andalucía, las acciones de análisis y tratamiento de intervención en los bienes de nuestro Patrimonio, aplicando una metodología específica y unos criterios de actuación acreditados por principios teóricos, conceptuales y deontológicos, internacionalmente aceptados por las instituciones y los profesionales de la conservación-restauración de bienes culturales.

Entre sus planteamientos fundamentales se pueden destacar los siguientes criterios:

- Respetar la singularidad de los bienes culturales.

- Intervenir en función de las necesidades del bien cultural.

- Afrontar la intervención desde un enfoque interdisciplinar.

- Adoptar siempre el principio de "la mínima intervención" (mantener antes que intervenir).

- Aplicar el concepto de reversibilidad en los tratamientos y materiales empleados.

La adopción de criterios normalizados tuvieron en España los primeros antecedentes en 1933: aunque no se mencionan expresamente, se fijan por la Junta Superior del Tesoro Artístico, que hace suya la iniciativa para "la organización y el desarrollo de los servicios de consolidación y conservación de monumentos, (...) teniendo en cuenta los recursos disponibles y las necesidades más urgentes, (y) fijará las demarcaciones y escalonará los trabajos (...)"”. Entre sus criterios de intervención determina:

"Se proscribe todo intento de reconstitución de los monumentos, procurándose por todos los medios de la técnica su conservación y consolidación, limitándose a restaurar lo que fuere absolutamente indispensable y dejando siempre reconocibles las adiciones"

Comprendemos la vigencia, no terminológica, pero sí de planteamientos éticos de esta cita, en el respeto al original, rechazando las reconstrucciones, propiciando la máxima conservación y la mínima intervención, y teniendo en cuenta el reconocimiento de añadidos para no crear falsos históricos.

Otros criterios que debemos destacar, son los referentes a la compatibilidad incluso estética de materiales y su reversibilidad, tal y como se señala en la actual Ley de Patrimonio de Andalucía ${ }^{10}$.

Hoy tenemos plenamente asimilada la necesidad de conocer. Para una acertada actuación es imprescindible encontrar la esencia y los valores de la obra (incluso los posibles valores futuros que no conocemos), ya que tenemos la obligación de actuar para su transmisión. Por tanto, el reconocimiento de todos los valores que integran la obra y su puesta en valor, nos permite entender que no es suficiente un mantenimiento de los fragmentos, es necesario conservar su autenticidad. 
"La restauración debe dirigirse al restablecimiento de la unidad potencial de la obra de arte, siempre que esto sea posible sin cometer una falsificación artística o una falsificación bistórica, y sin borrar buella alguna del transcurso de la obra de arte a través del tiempo.” (Brandi 2002: 17).

"No se puede conservar si no se conocen hasta el fondo por lo que son y por lo que valen, las obras que hay que conservar. No se puede trabajar con esas obras confiando sólo en nuestro gusto estético, por muy refinado que éste sea, o en nuestra babilidad técnica."(Baldini 1997: 5).

\section{Los criterios de actuación en cerámica aplicada a arquitectura}

Tras la exposición general del estado de la cuestión, a manera de preámbulo, proponemos a continuación una metodología de estudio en tres fases. Por un lado se ha abordado el análisis de los principales acuerdos internacionales, para acercar sus principios a la tipología de los bienes que nos ocupan: la cerámica. En segundo lugar se examina la casuística relevante de los últimos años, a través de actuaciones divulgadas en publicaciones especializadas. Y por último, se exponen a modo de conclusión, las fases y metodología de trabajo aplicados en un caso que ofrecemos como punto de partida para formular las bases de una futura normalización.

\section{- Criterios generales: legislaciones, cartas, directrices profesionales y código ético}

La progresiva ampliación del concepto patrimonio cultural, ha dado lugar a las continuas revisiones y actualizaciones de los acuerdos internacionales que velan por su conservación.

En la Carta de Atenas de 1931, sólo se hacía referencia a monumentos, obras maestras y ruinas. En la Carta de Venecia de 1964 se aplica la necesaria protección no solo a las grandes obras:

"La noción de monumento bistórico comprende tanto la creación arquitectónica aislada, como el ambiente urbano o paisajistico que constituya el testimonio de una civilización particular, de una evolución significativa o de un acontecimiento histórico. Esta noción se aplica no sólo a las grandes obras, sino también a las obras modestas que con el tiempo hayan adquirido un significado cultural." Art.1.

En la Carta del Restauro de 1972 el ámbito de salvaguarda se hace ya extensible a todas las obras de arte:

"Todas las obras de arte de todas las épocas, en la acepción más amplia, que va desde los monumentos arquitectónicos a los de pintura y escultura, aunque sean fragmentos, y desde el hallargo paleolítico a las expresiones figurativas de las culturas populares y del arte contemporáneo (...)” Art.1.

En este documento, en las Instrucciones para la salvaguardia y restauración de Antigüedades, encontramos por primera vez una mención expresa a los materiales cerámicos, aunque en el contexto de los restos procedentes de yacimientos arqueológicos, en las prospecciones terrestres o subacuáticas. Aquí se incluyen ya algunas pautas preventivas para conservar la integridad de terracotas, materiales cerámicos arqueológicos o esculturas vidriadas.

(...) "En estas especiales condiciones de rescate así como en las exploraciones arqueológicas terrestres normales deberán considerarse las especiales exigencias de conservación y restauración de los objetos según su tipo y su material, por ejemplo, para los materiales cerámicos y para las ánforas se tomarán todas las precauciones que permitan la identificación de los posibles residuos o buellas de su contenido, que constituyen datos preciosos para la historia del comercio y de la vida de la antigüedad; además, deberá prestarse especial atención al examen y fjación de posibles inscripciones pintadas, especialmente en el cuerpo de las ánforas." (Anexo A). 
Será gracias a la UNESCO, a través de las Recomendaciones sobre Protección de los Bienes Culturales Muebles de 1978, cuando por primera vez de forma clara y precisa, se establezca interés por los materiales cerámicos, por sí mismos o por su interés artístico, y no solo por su contexto arqueológico o por su valor documental, antropológico o etnológico. En estas recomendaciones, en su punto 1(a), se señalan dentro del concepto "bienes culturales muebles", entre otras categorías, las siguientes:

“(ii) Los objetos antiguos tales como instrumentos, alfarería, inscripciones”...

"(vi) los bienes de interés artístico, tales como: (...) -obras de arte y artesanía hechas con materiales como el vidrio, la cerámica, el metal, la madera, etc."

Y finalmente, en la Carta de 1987 de la Conservación y Restauración de los Objetos de Arte y Cultura, se aplica el ámbito de protección y actuación a todos los objetos de interés artístico, histórico y en general cultural. Y, en nuestro interés particular a

"... obras de figuración plana sobre cualquier tipo de soporte (mural, de papel, textil, lígneo, de piedra, metálico, cerámico, vítreo, etc.) (...) aislada o inserta en contextos más amplios.” Art. 1.

Cuestión que debemos destacar por su equiparación junto a otras obras de figuración plana en otros soportes.

A partir del reconocimiento de su interés artístico y de su condición de autenticidad ${ }^{11}$, para ser valorada como Bien Cultural, las leyes de protección del patrimonio y los poderes públicos son los que establecen los criterios generales para su preservación. Las recomendaciones internacionales, son las que normalizan la actividad de la conservación-restauración. Y finalmente las directrices profesionales y el código ético de la profesión, las que guían la actuación del conservadorrestaurador.

Bajo estos parámetros, nos situamos como conservadores-restauradores, responsables del cuidado y de la transmisión a las generaciones futuras de "nuestro" patrimonio cultural. Somos los conservadores-restauradores quienes debemos llevar a cabo el planteamiento estratégico de la actuación. Dentro de nuestras funciones hemos de destacar las siguientes: examinar, emitir un diagnóstico y hacer la propuesta de tratamiento. Finalmente, nuestra es la última responsabilidad en los tratamientos de conservación-restauración.

En la búsqueda de normalización, de la unificación de criterios de intervención, hemos seleccionado algunos apartados de las recomendaciones de distintos organismos internacionales ${ }^{12}$, que pueden orientar nuestra intervención sobre los materiales cerámicos. En primer lugar exponemos algunos criterios extraídos de la legislación española en materia de patrimonio, con mención explícita de la actuación sobre cerámica:

La cerámica aplicada a la arquitectura tiene, según la Ley de Patrimonio Histórico Español de 1985, la consideración de bien inmueble, por considerarse consustancial al edificio, y sólo se podrá eliminar, con carácter excepcional, si supone una degradación o impide su correcta interpretación histórica:

“(...) tienen la consideración de bienes inmuebles (...) cuantos elementos puedan considerarse consustanciales con los edificios y formen parte de los mismos o de su entorno o lo bayan formado, aunque en el caso de poder ser separados constituyan un todo perfecto de fácil aplicación a otras construcciones o a usos distintos del suyo original, cualquiera que sea la materia de que estén formados y aunque su separación no perjudique visiblemente al mérito bistórico o artístico del inmueble al que están adheridos." (Título II. De los Bienes Inmuebles. Artículo 14.1). 
"Las restauraciones de los bienes a que se refiere el presente articulo respetarán las aportaciones de todas las épocas existentes. La eliminación de alguna de ellas sólo se autorizará con carácter excepcional y siempre que los elementos que traten de suprimirse supongan una evidente degradación del bien y su eliminación fuere necesaria para permitir una mejor interpretación histórica del mismo. Las partes suprimidas quedaran debidamente documentadas." (Título IV. Sobre la protección de los Bienes Muebles e Inmuebles. Artículo 39.3).

En nuestro entorno, la cerámica, como producto artístico o documento histórico, es una importante contribución que permanece en numerosos edificios civiles y religiosos, y que no puede sustituirse por ser una referencia de nuestra arquitectura regional. Y no sólo eso, deben mantenerse, con el auxilio de la ciencia y de la técnica, como se expresa en el caso de la comunidad andaluza en la legislación vigente. Igualmente se señala la necesidad del mantenimiento de las aportaciones de distintas épocas:

1. "La realización de intervenciones sobre bienes inscritos en el Catálogo General del patrimonio Histórico Andaluz procurará por todos los medios de la ciencia y de la técnica su conservación, restauración y rehabilitación.” (...)

2. "Las restauraciones respetarán las aportaciones de todas las épocas".

3. "Los materiales empleados en la conservación, restauración y rehabilitación deberán ser compatibles con los del bien (...)”. (Título II. Conservación y Restauración. Artículo 20.- Criterios de conservación).

En segundo lugar, haciendo una revisión de los acuerdos internacionales, aunque no se circunscriba especialmente a la problemática cerámica, hemos seleccionado algunos enunciados genéricos que se deben extrapolar a los materiales cerámicos y que podrían orientar nuestras intervenciones.

Un criterio acertado, actualmente integrado en lo que conocemos como conservación preventiva, es intervenir en las causas de la degradación, para impedir el progresivo avance del deterioro.

"(...) antes de cualquier obra de consolidación o de parcial restauración se haga una escrupulosa investigación acerca de la enfermedad a la cual se va a poner remedio.” (Carta de Atenas de 1931, IV).

"Conservación preventiva: Todas aquellas medidas y acciones que tengan como objeto evitar o minimizar futuros deterioros o pérdidas. Se realizan sobre el contexto o el área circundante al bien, o más frecuentemente un grupo de bienes, sin tener en cuenta su edad o condición. Estas medidas y acciones son indirectas - no interfieren con los materiales y las estructuras de los bienes. No modifican su apariencia. Algunos ejemplos de conservación preventiva incluyen las medidas y acciones necesarias para el registro, almacenamiento, manipulación, embalaje y transporte, control de las condiciones ambientales (luz. bumedad, contaminación atmosférica e insectos), planificación de emergencia, educación del personal, sensibilización del público, aprobación legal.” (ICOM. Nueva Delhi, 2008).

Reivindicamos la necesidad de un diagnóstico que nos acerque a las causas del deterioro. Entonces estaremos en disposición de intentar hacer una acertada intervención, donde no prevalezca el criterio estético cuando conlleve riesgos.

Entre los problemas más frecuentes en los edificios se encuentra la acción de la humedad y el deterioro salino. Por su proyección en los paramentos cerámicos, debemos destacar entre los criterios estas recomendaciones: 
"Sobre los métodos de protección de paramentos de piedra o de ladrillo no existe todavía un acuerdo satisfactorio. En efecto, la aplicación de resinas sintéticas impermeabilizantes es fiable sólo en parte en cuanto que éstas, por diferentes razones, al final no resultan enteramente bidrorrepelentes. En consecuencia parece que sólo pueden moderar el proceso de escoriación y descamado de las superficies pétreas, pero no evitar la acción del bielo ni de la sulfatación de los carbonatos de calcio, alli donde esta última se vea favorecida por la combinación entre los corpuisculos carbonosos (extendidos por infiltración en la porosidad de la piedra), oxigeno y lluvias ácidas."(Carta de 1987. Anexo B).

“(...) poner de relieve los aspectos del deterioro e individualizar sus causas. Antes de toda operación conservadora sobre las pinturas es necesario, en primer lugar, sanear el ambiente y eliminar toda causa de agresión.

(...) Si la intervención ha sido motivada por las condiciones termohigrométricas del lugar en general, o de las paredes en particular (...) como línea de conducta absoluta, no se deberá jamás volver a colocar la obra restaurada en el lugar original si éste no ha sido saneado adecuadamente." (Carta de 1987.

Anexo D: Advertencias generales para la restitución de obras restauradas a su primitivo emplazamiento).

\section{- Criterios aplicados: praxis y propuesta}

○ Casuística a través de publicaciones de actas de congresos, seminarios y revistas especializadas

Las intervenciones sobre el patrimonio cerámico aplicado en arquitectura, deben seguir los criterios generales emitidos en los distintos documentos mediante la aplicación de principios de ética refrendados.

A través del sondeo de las numerosas publicaciones y encuentros científicos, que poco a poco han ido aumentando, destacamos por la relevancia de sus aportaciones las siguientes:

- Actas del Seminario Rehabilitación de la azulejería en la arquitectura, celebrado en Valencia en 1993 (Coll 1995). Un ejemplar reflejo de la nueva valoración de la cerámica como Bien Cultural.

- El estudio y la conservación de la cerámica decorada aplicada en arquitectura. En el año 2000, la Unidad de Arquitectura y Sitios Arqueológicos del Centro Internacional para el Estudio de la Conservación y la Restauración de Bienes Culturales (ICCROM) y la Academia de España en Roma inician un proyecto, que culmina con esta publicación (Alva 2003). De carácter científico e interdisciplinar, expone el estudio, documentación y conservación del elemento cerámico vidriado en el contexto arquitectónico, advirtiendo de su falta de valoración ${ }^{13}$.

- International Seminar. Conservation of glazed ceramic tiles. Research and practise, celebrado en Lisboa, en 2009. A destacar entre los referentes más recientes. En esta convocatoria se hizo una revaloración de la cerámica, promoviendo también la normalización de los protocolos de ensayos específicos para la azulejería, la definición de su propia patología y la regulación de su metodología de intervención.

Comprobamos cómo las publicaciones relativas al estudio, caracterización, diagnóstico y actuaciones sobre material cerámico van paulatinamente mostrando una especial sensibilización entre los especialistas, que en distintos foros han mostrado las deficiencias de las propuestas generalizadas, reivindicando el mismo nivel e interés científico que el resto de los bienes culturales históricamente aceptados. 
- Notas básicas para una propuesta normalizadora

La propuesta básica que se incluye a continuación está fielmente inspirada en el protocolo de actuación sobre piedra, que publicara el IPHE (actualmente IPCE), en 2002: Los Criterios de intervención en materiales pétreos ${ }^{14}$ recogen las conclusiones de las jornadas especializadas celebradas con el propósito de aunar metodologías de trabajo sobre estos soportes. Y, como se verá, en algunos puntos sigue de forma textual sus recomendaciones, adaptando los comentarios al soporte cerámico.

\section{PROTOCOLO COMÚN PARA IDENTIFICACIÓN, CATALOGACIÓN Y CARACTERIZACIÓN}

\section{A- RECONOCIMIENTO PREVIO: EXAMEN ORGANOLÉPTICO}

\section{B- ESTUDIOS PRELIMINARES}

- Documentación histórica, artística y técnica del inmueble y del bien objeto de intervención

- Registro fotográficos (general, macrofotografías, rasante, etc.)

- Estudio de despieces, diseño, unidades ornamentales, ritmos de repetición, etc.

- Documentación gráfica (registros de ubicación, mapas de daños y planimetrías)

- Muestreo: análisis morfológico, cualitativo y cuantitativo de esmaltes, bizcochos y morteros

- Identificación de agentes de deterioro, localización y extensión de los daños

- Diagnóstico y propuesta de actuación

\section{C- CRITERIOS DE INTERVENCIÓN}

- En primer lugar se determinará el criterio a seguir, que se ajustará en todo momento a los términos marcados por la legislación vigente y las recomendaciones de las Cartas Internacionales, así como a la metodología ortodoxa de trabajo, siendo prioritario el máximo respeto al original.

- En cualquier caso se tenderá a respetar las características estructurales y formales del objeto con las naturales adiciones del tiempo.

- Siempre que sea posible, se recurrirá a cualquier documento, gráfico o escrito, que aporte datos fidedignos del aspecto primitivo de la obra. 


\section{D- OPERACIONES COMÚNES EN LOS PROCESOS DE INTERVENCIÓN SOBRE} AZULEJERÍA (RECOMENDACIONES)

\section{TRATAMIENTO DE AZULEJOS DESDE ANVERSO}

Limpiezas manuales, mecánicas o químicas

Eliminación superficial de depósitos

Eliminación de las protecciones previas

Eliminación de antiguos morteros

Limpieza de juntas

Adhesión de lascas de vidriado

Fijación de esmalte

Reintegración de lagunas de esmalte

Reintegración de lagunas en esmalte y soporte

Protección final de las reintegraciones

Reproducción de piezas

\section{Recomendaciones}

- Se considera indispensables realizar ensayos de idoneidad en cada una de las operaciones.

- Se deberán realizar pruebas previas de limpieza in situ para determinar la metodología específica, analizando su incidencia sobre la superficie. Se desaconseja el uso de cepillos metálicos, y el uso de ácidos.

- Para eliminar las sales se aconseja seguir la metodología ya experimentada para tratamiento de piedra (por inmersión o por impregnación con pulpa de papel humedecida en agua desionizada). En estos casos, se desaconseja la utilización de cloruro de bario u otras sales, cuyo objetivo es transformar las sales solubles en insolubles. Procedimientos que suelen provocar la formación de productos nocivos para la conservación de los elementos cerámicos y los morteros. 
- Cuando se trate de restituir funciones estructurales al elemento, se deberá realizar la reintegración con nuevas piezas cerámicas, que contengan los criterios de reconocimiento, idoneidad y compatibilidad de materiales.

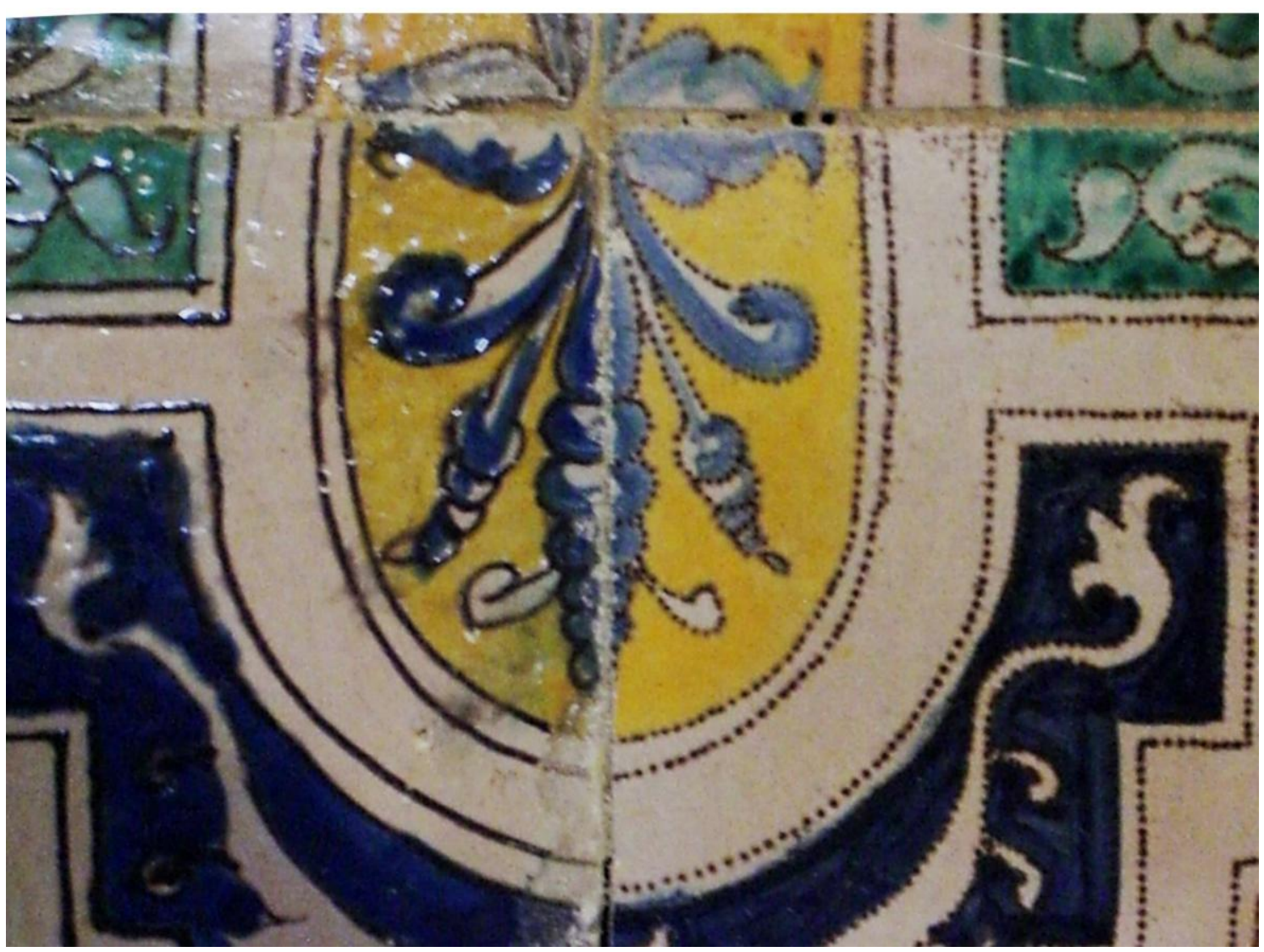

Figura 6. Reintegración de faltantes con nuevas piezas cerámicas: Las nuevas piezas se realizan con un criterio de reconocimiento, mediante el punteado de la línea de perfilado, para evitar un falso histórico (J.J. Lupión).

- Se debe tender al uso de materiales y técnicas tradicionales y siempre que sea posible las reintegraciones se realizarán con material de naturaleza similar y características compatibles con las del original.

- Serán innecesarias las reintegraciones cuando las faltas o pérdidas de materia, una vez realizado el proceso de limpieza, queden integradas en el efecto cromático y estético del conjunto y no afecten a la conservación ni al reconocimiento del objeto o elemento.

- Se evitarán las reintegraciones formales ideales, ciñéndose únicamente a la reposición del volumen arquitectónico y limitándose exclusivamente a los bordes de la falta. Serán siempre discernibles pero integradas y se evitarán las adiciones miméticas.

- Las sustituciones únicamente serán justificadas en aquellos elementos que por su avanzado estado de deterioro hayan dejado de cumplir su función estructural o de protección o, en casos excepcionales, en aquellos cuya conservación in situ resulte probadamente imposible. 


\section{DESMONTAJE Y EXTRACCIÓN}

Engasado de protección

Numeración de piezas

Extracción de piezas

Embalaje y protección provisionales

Traslado

\section{Recomendaciones}

- La extracción de los elementos cerámicos estará plenamente justificada en los criterios de intervención, y se realizará de forma esporádica.

- La selección de los materiales para su protección seguirán las normas de prevención y reversibilidad adecuadas al caso.

- Se considera indispensables realizar planimetrías y toda documentación pertinente, que testimonien la ubicación y distribución original de cada elemento.

- Todas las piezas deben ser identificadas y numeradas por medio de signos legibles.

- Se diseñaran los medios idóneos para el transporte y almacenaje de los azulejos durante el proceso de intervención.

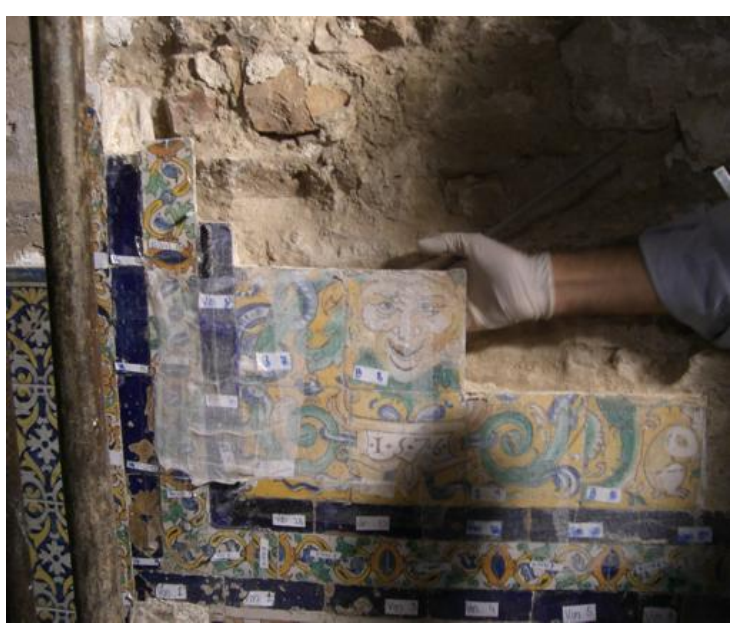

Figura 7. Metodología de extracción: siglado y engasado de protección. En este caso las circunstancias propiciaron la extracción de cada pieza sin ejercer presión sobre los azulejos removiendo manualmente el mortero para evitar roturas (J.J. Lupión). 


\section{TRATAMIENTO DEL REVERSO}

Limpiezas manuales

Limpiezas mecánicas

Limpiezas químicas

Eliminación de sales del soporte

Consolidación de paños

Consolidación del bizcocho

Tratamiento preventivo de ataque microbiano

Señalización indeleble

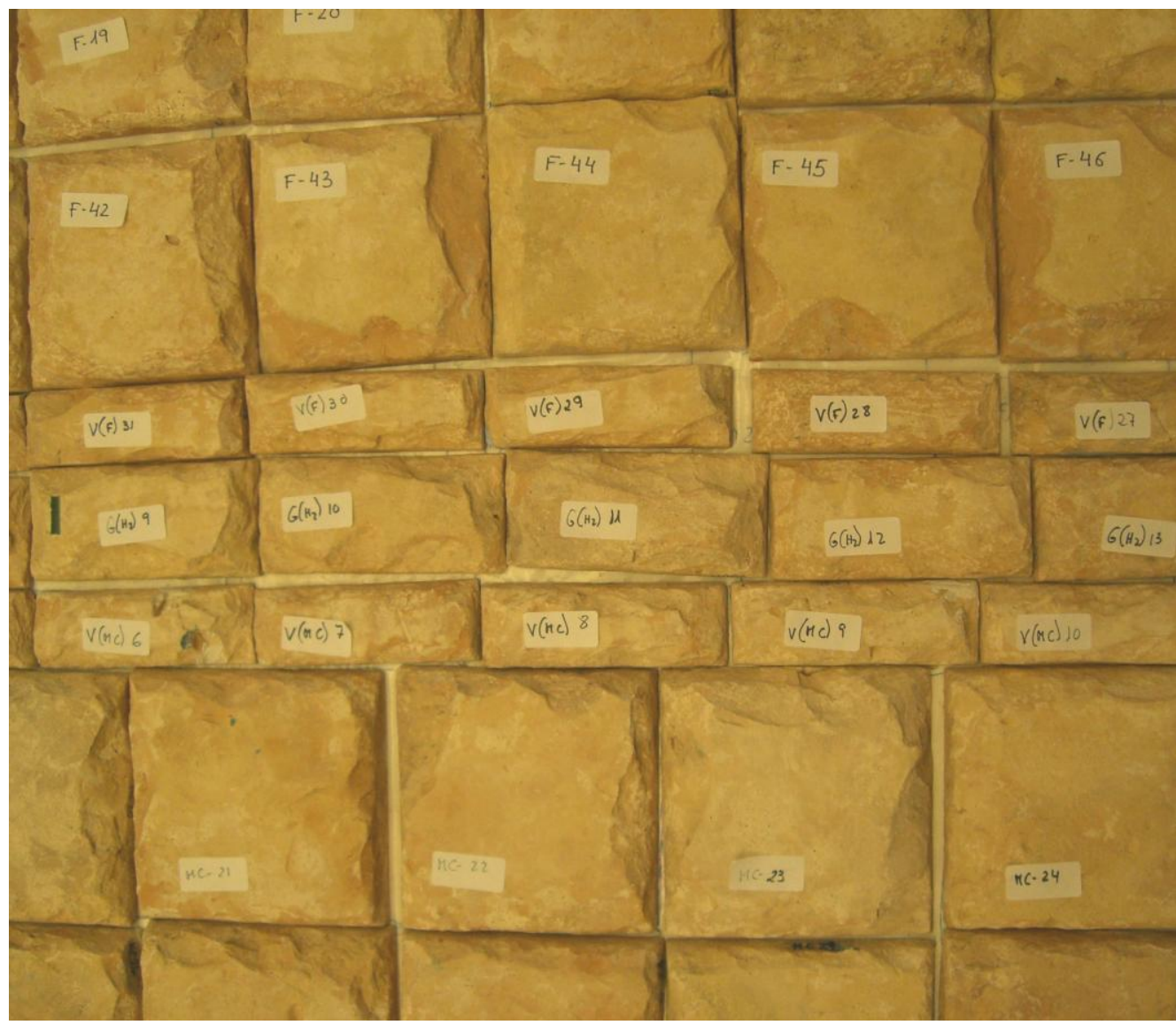

Figura 8. Vista trasera de un conjunto de azulejos tras la intervención, con siglado identificativo de cada pieza (J.J. Lupión). 


\section{Recomendaciones}

- La facilidad de la eliminación de las sales está relacionada con su solubilidad. Por ello, su caracterización es imprescindible.

- La finalidad de la desalinización es la eliminación de las sales solubles depositadas sobre la superficie del azulejo o en su interior. Las sales solubles son uno de los agentes de alteración más nocivos porque generan microfisuraciones, disgregación granular y pérdida de cohesión de los materiales cerámicos y pueden comprometer el éxito de tratamientos posteriores de consolidación o hidrofugación.

- En el caso de que no se pudieran eliminar las sales, no se deberá proceder a la consolidación o hidrofugación del soporte ni del vidriado.

- En los tratamientos de consolidación del bizcocho de los materiales cerámicos, se intenta devolver la cohesión interna. Es necesario la máxima penetración del producto, la adhesión entre la zona alterada y sana del material para evitar la formación de películas superficiales. Solo se hará en casos concretos y de forma excepcional.

\section{REUBICACIÓN Y NUEVO MONTAJE}

Tratamiento del muro, solerías o techumbres

Estratos de intervención

Construcción de cámara de separación

Fabricación de nuevos soportes autoportantes

Reintegración de morteros

Colocación de paños o piezas

Rejuntado de paños

\section{Recomendaciones}

- En el caso de que fuera necesario sustituir los morteros, se procederá a estudiar su composición, dosificación, granulometría y textura, ya que representan un documento y como tal aportan información sobre la historia del edificio.

- El entonado de los morteros se realizará en masa, con pigmentos minerales, ajustando las características de textura y color al soporte.

- En todas las operaciones se recomienda la utilización de productos del mismo fabricante con el fin de evitar incompatibilidades derivadas de su formulación. 
- En aras del control de calidad de los materiales empleados, se utilizarán productos con etiqueta de composición, recomendándose el uso de productos originales -no modificados por intermediarios- y el seguimiento de las instrucciones de uso del propio fabricante.

- Se recomienda el relleno de grietas y fisuras, así como de pequeños faltantes de vidriado o de soporte, con objeto de favorecer la protección del conjunto de material cerámico, evitando las vías de penetración del agua, y la pérdida paulatina de bordes.

- Las reintegraciones a base de mortero se realizarán cuando el área o volumen a reponer sea de pequeña extensión con relación al tamaño del elemento u objeto sobre el que se interviene y el uso del mortero no suponga una merma en la resistencia mecánica del elemento.

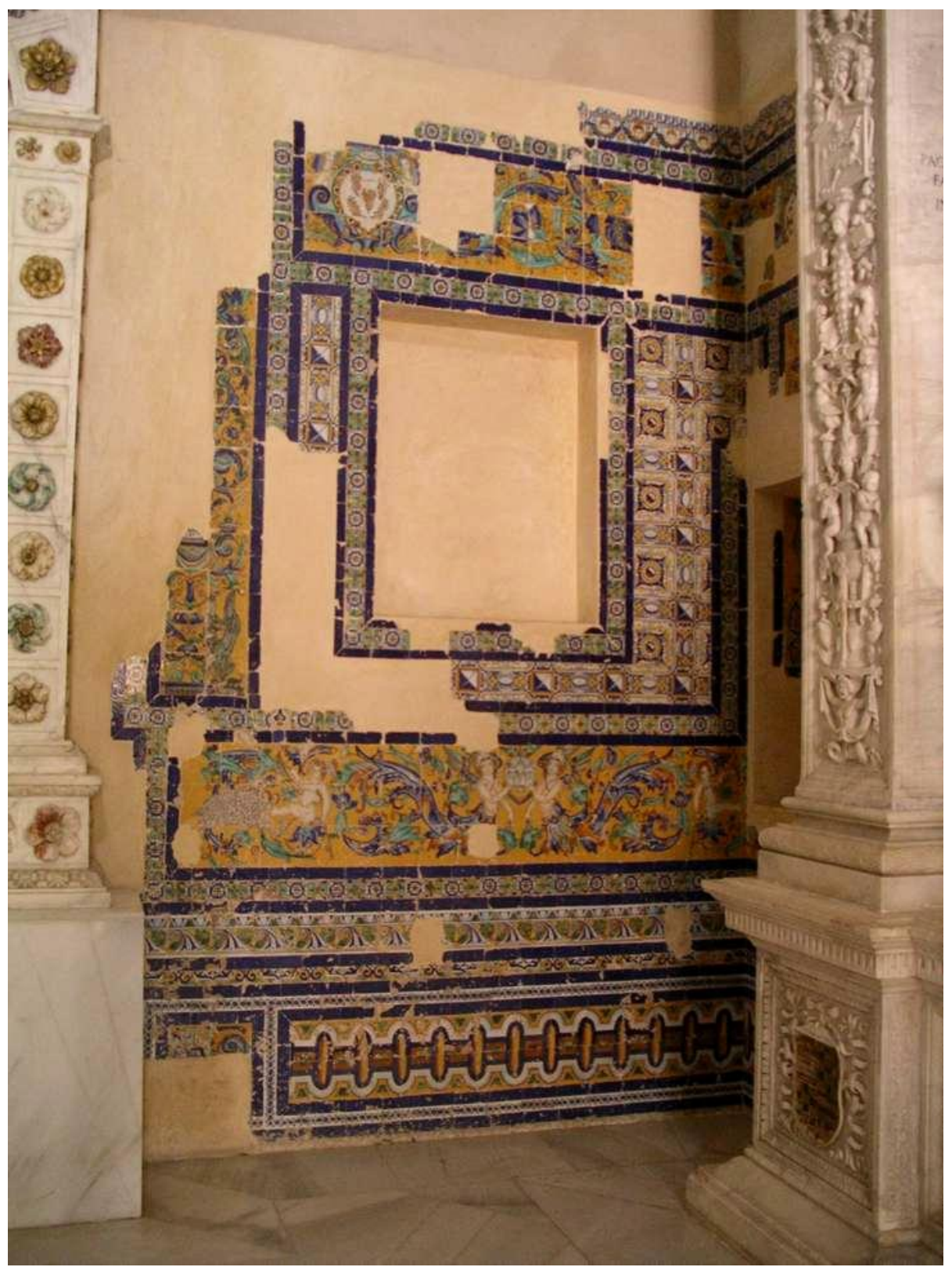

Figura 9. Caso de reintegración excesiva de morteros en grandes lagunas. Monasterio de la Cartuja, Sevilla (J.J. Lupión). 
- La aplicación de los morteros de junta estará siempre justificada por razones de protección y conservación.

- Los nuevos morteros deberán ser compatibles con los morteros originales en lo que se refiere a la naturaleza del aglomerante, dosificación y tipo de árido. Se recomiendan morteros de restauración con similar o superior volumen poroso (tipo macroporosidad), así como de comportamiento mecánico compatible con el material cerámico.

- Los morteros aconsejados son los de cal y arena de composición silícea, siguiendo los procesos tradicionales.

- Se evitarán aquellas capas de protección compuestas por ceras, naturales o sintéticas, que favorezcan la adherencia de polvo sobre la superficie.

- Considerando la importancia de las condiciones ambientales, del sistema y del modo de aplicación en el resultado final del tratamiento, los productos serán manipulados por restauradores especializados.

- Se deberá tener en cuenta que las condiciones de temperatura y humedad, tanto ambientales como del soporte, sean las adecuadas para garantizar una correcta aplicación del producto, según las indicaciones del fabricante, así como que vaya precedida de la limpieza y desalinización del soporte.

\section{MANTENIMIENTO Y CONSERVACIÓN PREVENTIVA}

Controles medioambientales

Revisiones periódicas de mantenimiento

Diseño de expositores, escaleras o andamiajes, marcos o mamparas de protección

Diseño de cajas de almacenaje, peines, estanterías, etc.

Control de seguridad

Divulgación

La Carta de 1987 define Mantenimiento como "el conjunto de actuaciones programáticamente recurrentes, encaminadas a mantener los objetos de interés cultural en condiciones óptimas de integridad y funcionalidad, especialmente después de que bayan sufrido intervenciones excepcionales de conservación o restauración".

"La programación y ejecución de ciclos regulares de mantenimiento y de control del estado de conservación de un monumento arquitectónico es la única garantía de que la prevención sea oportuna y apropiada a la obra, en lo que se refiere al carácter de las intervenciones y a su frecuencia". 


\section{Recomendaciones}

- Los productos hidrofugantes deberán aplicarse cuando existan garantías de que los problemas de humedad (derivados de la ascensión capilar o de un deficiente funcionamiento de los sistemas de recogida y evacuación de aguas) así como los movimientos de sales solubles que puedan afectar a las zonas tratadas, se hayan erradicado.

- Se efectuarán controles de eficacia durante el desarrollo de todas las operaciones.

- Caso práctico: Intervención en revestimiento de azulejería del siglo XVI, en la Capilla de Ánimas de la Iglesia de Santa Ana de Triana, en Sevilla (España)

Tipología de la obra: Zócalo de azulejería

Ubicación: Capilla de Ánimas, Iglesia de Santa Ana de Triana, Sevilla (España)

Propietario / institución responsable: Iglesia de Santa Ana de Triana

Autor / atribución: Firma: “AL”. Atribución a Alonso García

Fecha: 1577

Estilo: Pisano

Dimensiones: Lateral izquierdo: longitud 2,94 $\mathrm{m}$ x altura $2,52 \mathrm{~m}$

Frente: $\quad$ longitud $4,63 \mathrm{~m} \mathrm{x}$ altura $2,52 \mathrm{~m}$

Lateral derecho: $\quad$ longitud $1,58 \mathrm{~m} \times$ altura $2,52 \mathrm{~m}$

Materiales y técnicas:

Soporte: Azulejo manual.

Superficie: Vidriada. Técnica de azulejo policromo plano, pintado sobre cubierta de esmalte opaco.

Estado de conservación: Muy deficiente. Desplomes continuados. Riesgo inminente de desprendimientos. Patología diversa. Pérdidas localizadas de esmalte y soporte a relacionar con depósitos salinos.

Fechas y duración aproximada de los estudios y de la intervención:

- Documentación y estudios preliminares: 1 semana

- Duración del tratamiento de conservación y restauración: 10 semanas

- Elaboración del informe, memoria, gráficos y fotografías: 2 semanas

\section{Perfil del equipo de estudio y de intervención:}

- Dirección del Proyecto: 1 licenciado en Bellas Artes, especialista en Conservación y Restauración, especialista en Material Cerámico. 
- Documentación: 1 conservador-restaurador, 1 historiador y 1 fotógrafo.

- Tratamiento de conservación: 10 alumnos en prácticas de formación en Conservación y Restauración (1 licenciado en Bellas Artes, especialista en Conservación y Restauración, 1 licenciado en Arqueología, 8 especialistas en materiales cerámicos), 1 químico, 1 arquitecto.

\section{Origen del proyecto}

Desde su inicio, hace poco más de 15 años, la Escuela de Artes y Artesanía "Della Robbia", se ha dedicado al estudio y promoción de los oficios cerámicos relacionados con el Patrimonio. Desde hace poco más de 5 años, el Departamento de Pintura Cerámica y Azulejería realiza prácticas formativas bajo dirección facultativa en tratamientos de conservación-restauración sobre materiales cerámicos aplicados al patrimonio arquitectónico.

Las actuaciones emprendidas vienen avaladas por un equipo multidisciplinar, acompañando cada proceso con análisis científicos y documentación histórica.

\section{Contexto de la intervención}

El panel cerámico llega al Departamento de Azulejería de la Escuela "Della Robbia", a través del acuerdo entre la Delegación de Empleo de la Junta de Andalucía y la Iglesia de Santa Ana.

La edificación de la iglesia de Santa Ana se inicia entre 1276 y 1280, fundada por Alfonso X, y se concluye a principios del siglo XIV. A lo largo de su historia ha sufrido reedificaciones parciales (siglo XIV), remodelaciones (tras el terremoto de 1755) y recientes restauraciones (en 1975, desaparición de gran parte de su ornamentación interior y de sus revestimientos cerámicos).

Fue durante el último tercio del siglo XVI, cuando se levantaron en el interior de la iglesia dos capillas a los pies de la nave central. Una de ellas, en el lado de la epístola, es la Capilla de Ánimas, que conserva sus paramentos revestidos de azulejería de la época. Se accede a través de una interesante reja de hierro (1591) de dos tramos, decorada con balaustres, y un tondo dedicado a San Miguel, que daba título a esta hermandad de Ánimas.

El interior de la capilla está revestido por un alto zócalo de azulejos (altura 2,52 m), fechado en 1576, y firmado con las siglas " $\mathrm{A}{ }^{\circ} \mathrm{L}$ ", que parece corresponder al maestro azulejero Alonso Gacía. Este zócalo es uno de los primeros conjuntos que se mantienen, tras la recuperación de la técnica plana que trajo Pisano a Sevilla, a principios del siglo XVI. Es, además, un ejemplo característico, referido y reproducido numerosas veces en la bibliografía.

El estado de conservación que presenta el zócalo era lamentable:

- El conjunto mostraba una deficiente adhesión al muro, con desprendimiento de numerosas piezas, riesgo de desplome, y numerosas pérdidas continuadas en el tiempo. También presentaba numerosas pérdidas de vidriado, debidas en su mayor parte a las sales transmitidas por el inmueble.

- En el lateral izquierdo presenta una pérdida de numerosas piezas, por la apertura de una puerta. 
- En el lateral derecho, el deterioro ocasionado por sales transportadas por la humedad de capilaridad había ocasionado el saltado de esmaltes, disgregación de morteros y desplome de piezas. Estas piezas fueron sustituidas por otras ajenas al conjunto, utilizando morteros de cemento, que provocaron un aumento de la ya considerable pérdida de capa vítrea en el conjunto.

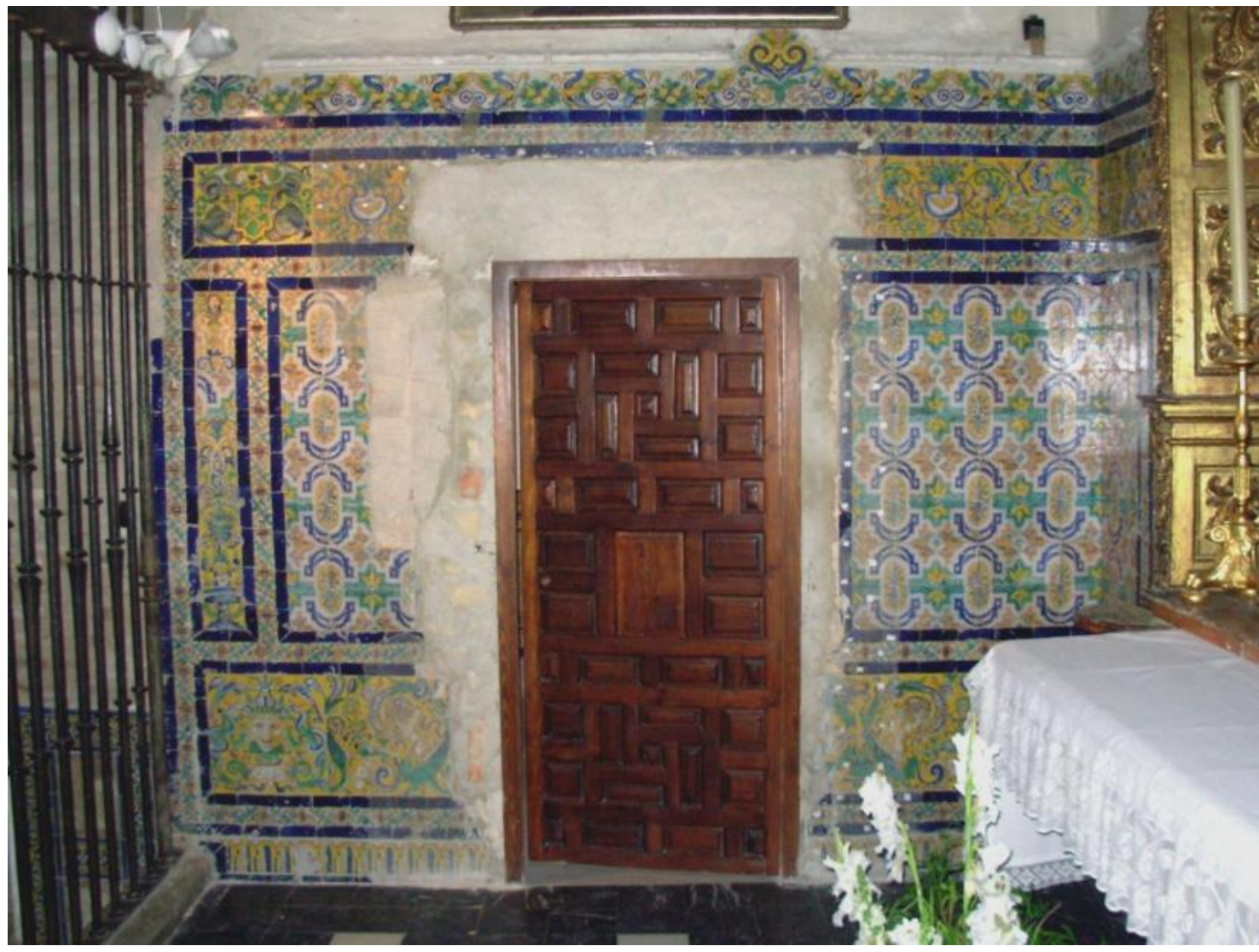

Figura 10. Lateral izquierdo antes de la intervención de la azulejería del siglo XVI, en la Capilla de Ánimas de la Iglesia de Santa Ana de Triana, en Sevilla (España) (J.J. Lupión).

Por la importancia de los restos y por el grave deterioro que dio lugar a pérdidas irreversibles, se decide una actuación de urgencia, que ponga fin a las causas del deterioro, controlando las humedades, actuando sobre los daños para restablecer la integridad del conjunto.

\section{Desarrollo de la propuesta de tratamiento}

La primera visita a la Capilla, tras ser solicitado su análisis y diagnóstico, consistió en una observación minuciosa y en el registro fotográfico de su estado, para dar comienzo a una valoración más detallada de su estado de conservación. A ello siguió la puesta en marcha del protocolo usual de búsqueda en archivos y bibliotecas para dar constancia de su pasado, origen e historia material. Asimismo se procede al muestreo para caracterización de materiales y agentes de deterioro. 
En un lento y exhaustivo trabajo de campo, se registraron los daños en un mapa de deterioros, que evidencia los numerosos fragmentos faltantes, algunas piezas completas, las pérdidas de esmalte (producidas por sales) y la presencia de roturas.

Tras las primeras conclusiones de las investigaciones, se redacta un primer informe y una primera evaluación sobre su estado, que culminan en la justificación de las propuestas de tratamiento.

El criterio adoptado se orientó hacia la conservación de todos los fragmentos originales, y a la recomposición con material cerámico de las lagunas faltantes, tanto piezas completas como fragmentos. Incluso en los casos en los que los restos no eran mayor del 5\%, se prima la conservación y aprovechamiento de piezas originales.

Los planteamientos o criterios generales que dirigen esta propuesta de intervención son:

- Máximo respeto al original, y a sus adiciones históricas

- Pautas para la Conservación preventiva

- Intervención prioritaria en las causas de la degradación

- Mínima intervención sobre los materiales constituyentes

- Reversibilidad y discernibilidad

- Compatibilidad química y estética

- Divulgación de la información relevante como medida de control de la calidad de la intervención y para la puesta en valor del conjunto.

\section{Fases de la intervención}

1. Documentación fotográfica antes del tratamiento.

2. Documentación gráfica, signado de piezas y planimetría.

3. Extracción de muestras para caracterización de materiales y patología.

4. Realización de mapas de deterioro, con distribución de los indicadores de deterioro.

5. Fijado previo de lascas levantadas en la capa de vidriado.

6. Protección mediante engasado puntual.

7. Se inician las tareas de retirada de piezas sueltas.

8. Desmontaje.

9. Control y siglado en lateral de la pieza, sobre pincelada de resina acrílica.

10. Embalaje y traslado a taller.

11. Unión y fijación de los fragmentos.

12. Retirada de protección.

13. Limpieza superficial. Medios mecánicos y sistemas acuosos principalmente.

14. Limpieza de anverso y reverso, retirada de restos de mortero.

15. Registro de las marcas del reverso. 
16. Desalinización por inmersión.

17. Secado envuelto en papel absorbente.

18. Documentación fotográfica de las distintas fases del tratamiento.

19. Consolidación.

20. Reintegración de piezas completas faltantes. Realización de nuevos azulejos, con criterio de reconocimiento.

21. Reintegración de piezas con fragmentos faltantes. Se elaboraron nuevos azulejos para ser adaptados mediante recorte a la laguna del original. Por el anverso, la unión se enrasaba con mortero de cal coloreado en masa con pigmentos "Marte", y por el reverso, en caso necesario, se añadía un refuerzo mínimo de material epoxídico.

22. Reintegración de grandes faltantes de vidriado. Se mantiene el soporte bizcocho incluso si la pérdida de la capa vítrea es de $100 \%$. Se aplica una fijación de la capa vítrea previamente y se reintegra con resina acrílica (tipo Paraloid B-72) y pigmentos "Marte".

23. Unión del conjunto de fragmentos. Los numerosos golpes recibidos que provocaron la pérdida de la capa vítrea policroma, se reintegraron con mortero de cal coloreado en masa, hasta enrasar los faltantes, y se protegieron y ajustaron con resina acrílica y pigmentos "Marte" en caso de necesidad en una reintegración.

24. Preparación para su ubicación final, bajo la dirección del arquitecto Sr. González de Canales: se construye un murete que alberga una cámara de vacío para evitar contacto con la estructura del inmueble.

25. Colocación de los azulejos, con mortero de cal "Cumen", bajo supervisión del conservadorrestaurador.

26. Retoques finales.

27. Documentación fotográfica tras finalización de tratamiento de cada una de las piezas por anverso y reverso.

28. Redacción del informe final incluyendo los análisis de laboratorio y la investigación histórica.

29. Difusión.

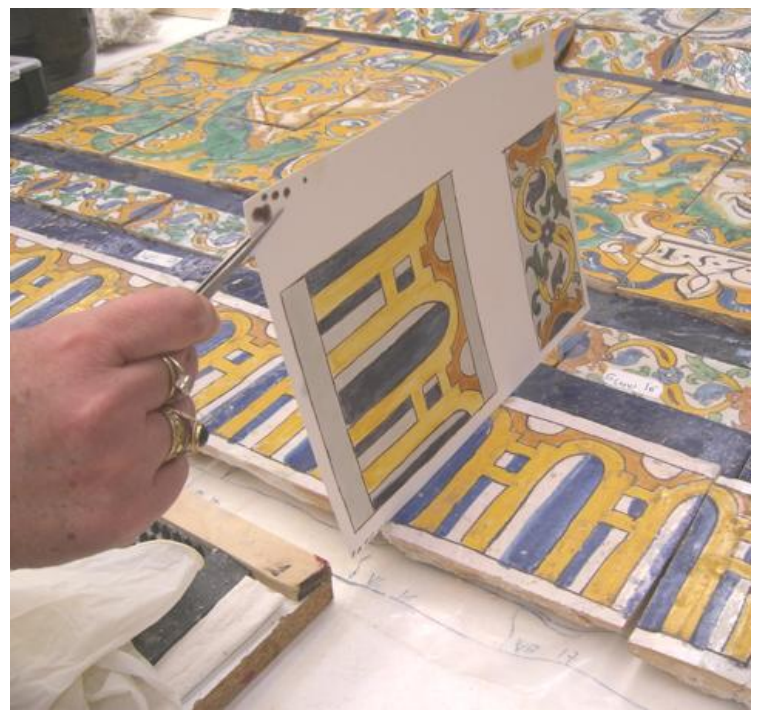

Figura 11. Dentro de la experimentación de nuevos métodos de reintegración, hubo lugar para la innovación mediante nuevos productos cerámicos: se realizaron pruebas con piezas de porcelanas sometidas a $1250^{\circ} \mathrm{C}$, de 0 '5 $\mathrm{mm}$ de grosor, diseñadas para resistir las condiciones atmosféricas más adversas. 


\section{Conclusión}

Este artículo pretende servir de iniciativa para la conformación de grupos de trabajo multidisciplinares que propugnen, como ya se ha hecho con la piedra, la pintura mural o los retablos, un acuerdo internacional en el que se recojan las principales recomendaciones que amparen la correcta preservación de un rico patrimonio extendido por amplias zonas geográficas, con una idiosincrasia y función que adquiere tintes tan variados.

La culminación de esta pequeña propuesta es la búsqueda de unos Criterios Específicos sobre material cerámico aplicado en arquitectura. Debemos concluir que las diferentes Cartas y Documentos emitidos a lo largo del siglo XX, han ejercido una enorme influencia positiva en las distintas legislaciones nacionales e internacionales (Martínez Justicia 2001: 409). Remarcamos la necesidad de profundizar razonablemente en los criterios a partir de los diferentes acuerdos en vigor, tomando como precedentes aquellos que pudiesen tener mayor relación con la cerámica aplicada en arquitectura.

Habremos de resaltar por último, la imperiosa necesidad de que se redacte una Carta sobre los Materiales Cerámicos, a partir de los antecedentes que se van formulando, a través de la buena práctica y las conclusiones teóricas que se van desprendiendo de la casuística relevante y de las aportaciones de los grupos de investigación. El mejor método para conseguir la concienciación de los especialistas es a través de los foros internacionales.

\section{Notas}

[1] El azulejo de cuenca o arista es un proceso de seriación, que por presión de una matriz sobre el barro fresco, eleva una arista que delimita el contorno del diseño. El espacio que queda entre las distintas aristas es una concavidad o cuenca que le da nombre y sirve de retención a los esmaltes.

[2] El ceramista es conocido también como Niculoso Pisano, firmaba Niculoso Francisco, y añadía Italiano o Pisano, por lo que puede entenderse que era oriundo de esta ciudad italiana. La nueva tipología cerámica es conocida como "azulejos planos polícromos" o "azulejos pisanos", y consiste en aplicar distintas mezclas de óxidos metálicos mediante pincel, sobre un azulejo cubierto por una capa de esmalte blanco opaco. El proceso finaliza con la cocción de las piezas, quedando fijados los óxidos al esmalte, y éste al azulejo. Francisco Niculoso Pisano trae esta nueva técnica a la par que un repertorio decorativo desconocido hasta ese momento en Sevilla, el grutesco.

[3] Diccionario de la Real Academia Española: Voz Criterio: norma para conocer la verdad / Juicio o discernimiento.

[4] BRANDI 2002: 130. "La conciencia de que las obras de arte, entendidas en la acepción más amplia (...), deben ser tuteladas de modo orgánico e igualitario, lleva a la elaboración de normas técnico-jurídicas que sancionen los límites en que se entiende la conservación, ya sea como salvaguarda y prevención, ya sea como intervención restauradora propiamente dicha."

[5] UNESCO. La Organización de las Naciones Unidas para la Educación, la Ciencia y la Cultura, fundada en 1945, está compuesta por 193 Estados Miembros. La acción normativa de la UNESCO en el área del patrimonio es doble. En el plano internacional: elaborar instrumentos jurídicos internacionales (convenciones, recomendaciones y declaraciones) con miras a una protección adecuada del patrimonio cultural. Y en el plano nacional: la UNESCO presta asimismo ayuda a los Estados Miembros, a petición de éstos y en el marco de sus programas y recursos, para la formulación y aplicación de una legislación nacional adecuada con miras a una protección efectiva de su patrimonio cultural. http://portal.unesco.org

[6] Moreno de Barreda 1999: 11. Aunque las actividades realizadas por el Consejo de Europa en materia de patrimonio Cultural, no han tenido una gran difusión en España, desde el comienzo de los años sesenta, el Consejo de Europa ha desarrollado una importante y trascendental programa de trabajo

122 
intergubernamental en la protección y puesta en valor del Patrimonio Cultural europeo, mediante Convenios internacionales, Resoluciones de la Conferencia de Ministros responsables del Patrimonio Cultural y Recomendaciones del Comité de Ministros a los gobiernos de los Estados miembros. http://www.coe.int/t/dg4/cultureheritage/heritage/Archeologie/default_en.asp

[7] Real Decreto 1132/2008, de 4 de julio, por el que se desarrolla la estructura orgánica básica del Ministerio de Cultura. Artículo 5. Dirección General de Bellas Artes y Bienes Culturales. Apartado 1. Párrafo j.: "El archivo y sistematización de los trabajos realizados y de la documentación disponible sobre patrimonio bistórico; la investigación y estudio sobre criterios, métodos y técnicas para su conservación y restauración, asi como la formación de técnicos y especialistas en conservación y restauración de los bienes inmuebles y muebles integrantes de dicho patrimonio." La creación del Instituto ICRBC se remonta al Real Decreto 565/1985, de 24 de abril y ratificado posteriormente el 25 de junio de ese mismo año por las Cortes Generales.

[8] Ley de 13 de mayo de 1933, modificada por la de 22 de diciembre de 1955 (Presidencia), sobre defensa, conservación y acrecentamiento del patrimonio histórico-artístico nacional (G. 25-5-1933 y B.O.E. 25-12-1955).

[9] Idem. Artículo 19 .

[10] Ley 14/2007, de 26 de noviembre, del Patrimonio Histórico de Andalucía. Artículo 20. Criterios de conservación.

"1. La realización de intervenciones sobre bienes inscritos en el Catálogo General del Patrimonio Histórico Andaluz. procurará por todos los medios de la ciencia y de la técnica su conservación, restauración y rehabilitación.

2. Las restauraciones respetarán las aportaciones de todas las épocas existentes, así como las pátinas, que constituyan un valor propio del bien. La eliminación de alguna de ellas sólo se autorizará, en su caso, y siempre que quede fundamentado que los elementos que traten de suprimirse supongan una degradación del bien y su eliminación fuere necesaria para permitir la adecuada conservación del bien y una mejor interpretación bistórica y cultural del mismo. Las partes suprimidas quedarán debidamente documentadas.

3. Los materiales empleados en la conservación, restauración y rehabilitación deberán ser compatibles con los del bien. En su elección se seguirán criterios de reversibilidad, debiendo ofrecer comportamientos y resultados suficientemente contrastados. Los métodos constructivos y los materiales a utilizar deberán ser compatibles con la tradición constructiva del bien.

4. En el caso de bienes inmuebles, las actuaciones a que se refiere el apartado 3 evitarán los intentos de reconstrucción, salvo cuando en su reposición se utilicen algunas partes originales de los mismos o se cuente con la precisa información documental y pueda probarse su autenticidad. Si se añadiesen materiales o partes indispensables, las adiciones deberán ser reconocibles y evitar las confusiones miméticas."

[11] Documento de Nara sobre la Autenticidad, redactado en la Conferencia de Nara sobre la Autenticidad en Relación con la Convención sobre el Patrimonio Mundial, en cooperación con la UNESCO, el ICCROM y el ICOMOS, celebrado en Nara (Japón), del 1-6 de noviembre de 1994. Artículo 13. "Dependiendo de la naturaleza del patrimonio cultural, de su contexto cultural, y de su evolución a través del tiempo, los juicios de autenticidad pueden vincularse al valor de una gran variedad de fuentes de información. Algunos de los aspectos de las fuentes pueden ser la forma y el diseño, los materiales y la sustancia, el uso y la función, la tradición y las técnicas, la ubicación y el escenario, asi como el espiritu y el sentimiento, y otros factores internos y externos."

[12] Patrimonio Mundial. UNESCO: La Convención de Patrimonio Mundial, Cultural y Natural (1972), es un tratado internacional aprobado por la Organización de las Naciones Unidas para la Educación, la Ciencia y la Cultura (UNESCO) que se propone promover la identificación, la protección y la preservación del patrimonio cultural y natural de todo el mundo considerado especialmente valioso para la humanidad. Para estas tareas cuenta con el apoyo de distintos órganos asesores como el Consejo Internacional de Monumentos y Sitios (ICOMOS), el Centro Internacional de Estudios de Conservación y Restauración de los Bienes Culturales (ICCROM) y la Unión Internacional para la Conservación de la Naturaleza y sus recursos (UICN). Carta de Atenas (1931), Carta de Venecia (1964), Carta del Restauro (1972), Nueva Carta del Restauro, de la Conservación y restauración de 
los objetos de arte y cultura (1987), Documento de Nara sobre Autenticidad (1994), Documento de Pavía (1997), Carta de Cracovia (2000), Principios para la preservación, conservación y restauración de las pinturas murales (2003).

[13] El mayor problema de la conservación de la cerámica en la arquitectura estriba en la falta de consideración "(...) de esos bienes, como elementos patrimoniales que son en sí mismos, por parte de los responsables de la conservación y restauración de la arquitectura (...)" que los hace sustituibles y provoca su desaparición. Coll, 2003: 97.

[14] "Criterios de intervención en materiales pétreos". Conclusiones de las Jornadas celebradas en febrero de 2002 en el Instituto del Patrimonio Histórico Español. En Bienes Culturales. IPHE, N², anexo, 2003.

\section{Bibliografía}

ALVA, A.; ALMAGRO, A. y BESTUÉ, I. (2003). El estudio y la conservación de la cerámica decorada aplicada en ARQUITECTURA. ICCROM Y ACADEMIA DE ESPAÑA EN ROMA.

BALDINI, Humberto (1997). Teoría de la restauración y unidad de metodología. Vol. I. Ed. Nerea/Nardini.

BRANDI, Cesare (2002). Teoría de la restauración. Madrid: Alianza Editorial.

CARTA DE 1987 DE LA CONSERVACIÓN Y RESTAURACIÓN DE LOS OBJETOS DE ARTE Y CULTURA. Anexo B. instrucciones para el desarrollo de la conservación, mantenimiento y restauración de las obras de interés arquitectónico. Metodología y técnicas de intervención. 5. Intervenciones de consolidación de piedra o de ladrillos vistos.

Anexo D. Instrucciones para la ejecución de intervenciones de conservación y restauración de obras de carácter plástico, pictórico, gráfico y de artes aplicadas. Previsiones que bay que tener en cuenta en la ejecución de intervenciones de conservación y restauración en pinturas murales y mosaicos.

CARTA DE LOS JARDINES HISTÓRICOS, elaborada en la VI Asamblea General de ICOMOS (Internacional Council of Monuments and Sites) en Florencia, septiembre de 1981.

CARTA DE LOS RETABLOS, Cartagena de Indias 2002.

CIRUJANO, Concha (2002): "Proceso de intervención en las portadas del Nacimiento y del Bautismo de la Catedral de Sevilla". Revista Bienes Culturales. IPHE, n 1.

CIRUJANO, Concha; SCHOEBEL, Ana; WORLD ART SERVICE FOUNDATION (2005); “Calidad en la conservación y restauración del patrimonio artístico". En Actas del II Congreso del GEIIC Investigación en Conservación y Restauración, celebrado del 9 al 11 de noviembre de 2005 en la Universidad de Barcelona.

COLL CONESA, Jaume (2003): "Reflexiones en torno a la conservación de la cerámica aplicada a la arquitectura", en El estudio y la conservación de la cerámica decorada aplicada en arquitectura. ICCROM y Academia de España en Roma.

COLL, Jaume, PÉREZ, Joseph y SCHÜTZ, Ilse (Coordinadores) (1995): Rehabilitación de la azulejería en la arquitectura. Actas del Seminario celebrado en Valencia del 25 al 27 de noviembre de 1993. Alicante: Asociación de Ceramología.

CRITERIOS DE INTERVENCIÓN EN MATERIALES PÉTREOS. Conclusiones de las Jornadas celebradas en febrero de 2002 en el Instituto del Patrimonio Histórico Español. En Bienes Culturales. IPHE, $\mathrm{n}^{\circ}$ 2, anexo, 2003. 
DESCAMPS, Françoise (Dir.) (2002.): "Metodología para la conservación de retablos de madera policromada", en Seminario internacional organizado por el Getty Conservation Institute y el Instituto Andaluz de Patrimonio Histórico. Sevilla: Junta de Andalucía. Consejería de Cultura. -The J. Paul Getty Trust. 241.

DIRECTRICES PROFESIONALES DE E.C.C.O.: LA PROFESIÓN Y SU CÓDIGO ÉTICO. Documento promovido por la Confederación Europea de Organizaciones de Conservadores-Restauradores y aprobado por su Asamblea General. Bruselas, 1 de marzo de 2002.

DIRECTRICES PROFESIONALES DE E.C.C.O. (II): CÓDIGO ETICO Documento promovido por la Confederación Europea de Organizaciones de Conservadores-Restauradores y aprobado por su Asamblea General . Bruselas, 7 de marzo de 2003.

DIRECTRICES PROFESIONALES DE E.C.C.O. (III): Documento promovido por la Confederación Europea de Organizaciones de Conservadores-Restauradores y aprobado por su Asamblea General. Bruselas, 2 de abril de 2004.

DOCUMENTO DE PAVÍA. Preservación del Patrimonio Cultural: Hacia el perfil europeo del conservadorrestaurador. Pavía 18-22 de octubre de 1997.

EL CONSERVADOR-RESTAURADOR: UNA DEFINICIÓN DE LA PROFESIÓN. CÓDIGO ÉTICO de Copenhague 1984. Documento aprobado por el Comité para la Conservación del ICOM (Consejo Internacional de Museos) en su $7^{\mathrm{a}}$ Reunión trienal celebrada en Copenhague en 1984.

International Seminar. Conservation of glazed ceramic tiles. Research and practise. Laboratório Nacional de Engenharia Civil, Lisboa, 15-16 de abril de 2009.

LEYES DEL PATRIMONIO HISTÓRICO ESPAÑOL. Ley 16/1985, de 25 de junio, Título IV. Sobre la protección de los Bienes Muebles e Inmuebles

LEY DE PATRIMONIO HISTÓRICO DE ANDALUCÍA, de 26 de noviembre de 2007. Título II. Conservación y Restauración.

LUPIÓN ÁlVAREZ, J. J.; ARJONILLA ÁlVAREZ, M.; SÁNCHEZ SOTO, P. J. y RUIZ CONDE, A (2006). "Los paños cerámicos del retablo de San Juan Evangelista de la Iglesia del Convento de Madre de Dios de Sevilla: autoría, patología y propuesta de intervención". En mus-A, Revista de los museos de Andalucía. Consejería de Cultura. Junta de Andalucía. Año VII, nº 7. Sevilla. 124 a 127

MARTÍNEZ JUSTICIA, Ma J. (1990): Carta del restauro, 1987. Málaga: Colegio Oficial de Arquitectos.

MORALES, Alfredo J. (1996): Patrimonio histórico-artístico. Conservación de bienes culturales. Madrid: Historia 16, Información e Historia, S.L.

MORENO DE BARREDA, Fernando (Dir.) (1999): El Patrimonio Cultural en el Consejo de Europa: Textos, Conceptos y Concordancias. Madrid: Ministerio de Educación, Cultura. Dirección General de Cooperación y Comunicación Cultural; Hispania Nostra; Boletín Oficial del Estado.

PRINCIPIOS PARA LA PRESERVACIÓN, CONSERVACIÓN Y RESTAURACIÓN DE PINTURAS MURALES, ratificada por la $14^{a}$ Asamblea General del ICOMOS (Internacional Council of Monuments and Sites), en Victoria Falls, Zimbabwe, octubre de 2003

RECOMENDACIONES SOBRE LA PROTECCIÓN DE LOS BIENES CULTURALES MUEBLES, aprobada por la Conferencia General de la Organización de las Naciones Unidas para la Educación, la Ciencia y la Cultura, en su 20ª reunión, celebrada en París, del 24 de octubre al 28 de noviembre de 1978.

TERMINOLOGÍA PARA DEFINIR LA CONSERVACIÓN DEL PATRIMONIO CULTURAL TANGIBLE. ICOM. Aprobada en la en la XV Conferencia Trianual celebrada en Nueva Delhi el 22-26 de septiembre de 2008 . 


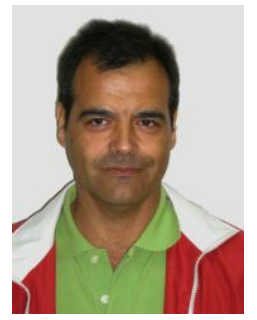

\section{J. J. Lupión Álvarez}

juanjolupion@gmail.com

Juan José Lupión Álvarez. Doctorando en Bellas Artes, Especialidad de Conservación y Restauración por la Universidad de Sevilla. Investigador del grupo Pintura y Nuevas Tecnologías. Jefe de Departamento de Pintura cerámica y Azulejería, y Profesor de Restauración de Cerámica del Patrimonio Arquitectónico. Dirección y gestión de cursos de especialización en materiales, técnicas y mecanismos de degradación de la pintura cerámica.

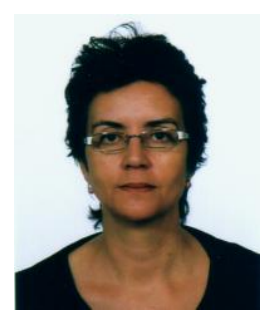

\section{Arjonilla Álvarez}

Departamento de Pintura

Facultad de Bellas Artes de la Universidad de Sevilla

Laraña 3, 41003 Sevilla

maar@us.es

María Arjonilla Álvarez. Doctora en Bellas Artes. Especialista en Pintura y Conservación y Restauración. Profesora de la Facultad de Bellas Artes de la Universidad de Sevilla. Investigadora del grupo Pintura y Nuevas Tecnologías, adscrito al Departamento de Pintura, con dirección de la línea de trabajo enfocada la Investigación interdisciplinar para la conservación del patrimonio a través del conocimiento material y técnico (Materiayarte).

Artículo recibido el 01/03/2010.

Artículo aceptado el 07/07/2010. 